\title{
Non-linear Effects of Investment in Road Infrastructure on the Structural Competitiveness of the Economy: The Case of Burkina Faso
}

\author{
Sigue Moussa \\ Department of Economics and Management, University Ouaga II, Ouagadougou, Burkina Faso \\ Email address: \\ msigue.reche@gmail.com

\section{To cite this article:} \\ Sigue Moussa. Non-linear Effects of Investment in Road Infrastructure on the Structural Competitiveness of the Economy: The Case of \\ Burkina Faso. International Journal of Economics, Finance and Management Sciences. Vol. 8, No. 3, 2020, pp. 98-107. \\ doi: 10.11648/j.ijefm.20200803.12
}

Received: May 15, 2020; Accepted: May 29, 2020; Published: June 8, 2020

\begin{abstract}
This article assesses the non-linear effects of investment in road infrastructure on the structural competitiveness of the economy of Burkina Faso. After selecting a period from 1980 to 2015, we estimated two econometric models. These are the quadratic estimation and that of the spline. The results obtained revealed a non-linearity between the structural competitiveness of the economy and investment in road infrastructure. Indeed, the quadratic estimation made it possible to identify a non-linearity in the shape of an inverted $U$ with an optimal threshold of $10.11 \%$. Regarding the spline estimation, it provided an optimal interval of $[5 \% ; 15 \%]$. In this interval, a $1 \%$ increase in investment in road infrastructure improves structural competitiveness by $0.018 \%$. However, beyond $15 \%$, a $1 \%$ increase in investment in road infrastructure leads to a decrease in structural competitiveness by $0.013 \%$. In view of these results, the implication of economic policy that emerges is that in order to benefit from optimal structural competitiveness, the share of investment in road infrastructure in the total investment budget must be between $5 \%$ and $15 \%$.
\end{abstract}

Keywords: Structural Competitiveness, Investment in Road Infrastructure, Non-linearity, Burkina Faso

\section{Introduction}

Since Smith, the costs of transport infrastructure in general and road infrastructure in particular are considered like a factor in promoting economic growth [1]. But this is a result of developments in endogen growth theory. This particular role has been a renewed interest. Thus, works of Aschauer until that of Barro and Kopp, investment in road infrastructure is apprehended as factor in improving the productive capacity and the overall productivity of the economy [2-5]. As such, it contributes to creating and building long-term global economy added value. It is on this basis that the new models of endogenous growth consider expenditure on road infrastructure as a factor self-sustained gain in productivity and long-term growth [4].

Examining the theory and empirical literature on the effectiveness of investment in infrastructures transport in general highlighted the need for optimal allocation of public investment budget. This topic is especially important for lowincome economies, since they will be still faced with a problem of allocation of public investments between social sectors, growth sectors and sectors with training effects. In other words, the issue of the optimal share of the state budget that must be allocated to different sectors to ensure sustainable economic performance remains a topical issue. For the World Bank, primarily public investment project, it is important to analyze the effectiveness of the share of the budget devoted to public infrastructure [6].

In the specific case of Burkina Faso, the data analysis of Burkina Faso's and the West African States Central Bank (WASCB) shows some signs of non-linearity between investment in road infrastructure and the structural competitiveness of Burkina Faso country's economy over the period from 1980 to 2015 [7, 8]. Indeed, the highest levels of competitiveness are observed between 2005 and 2015 . Paradoxically, this period includes investments less than 5\%, those between $5 \%$ and $10 \%$ and between $10 \%$ and $15 \%$. 
More specifically, the country recorded its highest levels of competitiveness when the share of the budget devoted to road investment was between $5 \%$ and $15 \%$ over the period from 2012 to 2013. Thus, it is possible to think the existence of an optimal share of investment in road infrastructure beyond which the contribution of investment in road infrastructure becomes low.

From all these observations, it is possible to think of the existence of a non-linear relationship between investment in road infrastructure and the structural competitiveness of the economy. This finding could be indicative of the existence of a possible delay effect linked to the emergence of a crowding-out effect that squeezes the productivity of the private sector beyond an optimal threshold for investment in road infrastructure. Also, it should be noted that to our knowledge, there exists no empirical having taken into account the non-linearity of investment in road infrastructure on the economy of Burkina Faso.

This is why this article aims to estimate the non-linear effects of road infrastructure investment on the structural competitiveness of the Burkina Faso economy. For this purpose, two specific objectives are pursued. First, it is necessary to estimate the optimal share of investment in road infrastructure in the total investment budget which allows to have an optimal structural competitiveness of Burkina Faso's economy. Secondly, there is a question of identifying an optimal investment interval in road infrastructure.

\section{Impact of Infrastructure Investment on Economic Competitiveness: Theoretical and Empirical Approach}

\subsection{Theoretical Approach}

The economic literature converges towards the hypothesis of a long-term non-linear relationship between public investment in general and economic competitiveness. Otherwise, the beneficial effects of road infrastructure investments on competitiveness are not instantaneous [9]. They appear first in the short term and then consolidate in the long term.

The hypothesis of the non-linearity between public infrastructure spending and economic growth established shows that, starting from an optimal threshold, the increase in the share of the total investment budget which is dedicated to transport infrastructure squeezes economy performance [10, [11]. In order to determine an optimal percentage of investment in road infrastructure that produces more pronounced effects on Burkina Faso's economic growth, it should be noted that it is similar to a Pareto optimum. Thus, this percentage of investment represents the optimal share of the total investment budget, which is devoted to road infrastructure so as to obtain a more optimal impact on the structural competitiveness of the economy. For Barro, the optimal size of investment is reached when the proportion of resources devoted to investment in public infrastructure is equal to its relative contribution to overall productivity [10].

Economic models on the productive role of public infrastructure spending in general and spending on road infrastructure especially in the competitiveness of the economy as a starting point the endogenous growth model. In this context, the role of road infrastructure in the competitiveness of economies is based on an analysis of the determinants of economic growth. This frame of reference explains the mechanism by which improved road infrastructure investments can increase factor productivity and ensure strong economic competitiveness [2-3, 4, 7, 5]. Here, spending on road infrastructure is likely to affect directly the stock of road infrastructure in the short term and therefore on the productive capacity of the economy. In the long term, the indirect effects of road investments can record a gain in overall productivity.

Like any investment in public infrastructure, road infrastructure expenditure is generally provided by the State because of the latter public nature. But authors have already highlighted the non-linear nature of the relationship between transport infrastructure spending and economic performance $[10,11]$. For them, the road investment must meet a phased development, since, beyond an optimal level, it is not financially or economically feasible, to anticipate the future. Thus, an improvement in the investment in road infrastructure can have more pronounced effects on the structural competitiveness of the economy, but an additional investment can have limited or even negative effects.

On the theoretical level, two factors explain the nonlinearity between public investment in general and the competitiveness of the economy. On the one hand, there is the decline in private sector productivity due to the crowding out effect and, on the other hand, the downward trend in the efficiency of investment in road infrastructure beyond optimal.

As regards the first factor, the financing of road infrastructure expenditure is generally made by borrowing and, as a result, is likely to cause an eviction effect. The explanation for this eviction lies in the fact that the overall logic of decisions is the balance between expenditures and revenues. The idea of crowding out relates to the fact that spending on road infrastructure is a cost borne by the community. The financing of this deficit is possible through additional expenditures from future savings that would have been used to finance the private projects investment which are likely to increase more productivity of the economy. The puncture made by the state on future private savings is driving up interest rates, which reduces the investment projects and private ousted by public investment in road infrastructure [13].

With regard to the loss of the efficiency of the investment in road infrastructure beyond the optimal part, Hulten proposes to distinguish two situations [14]. One upstream, characterized by poorly developed road infrastructure and the other downstream marked by fairly developed infrastructure generally requiring maintenance investments. In this case, an 
increase in investment in road infrastructure produces more positive effects on the overall productivity of the economy in the first situation than in the second. As a result, investment in road infrastructure positively affects the competitiveness of the economy, but this positive impact diminishes as the economy registers fairly developed road infrastructures. This opinion is shared by Kopp when he states that road infrastructure investments have a positive impact on overall productivity but that these investments do not guarantee a continuous increase in productivity [5].

\subsection{Syntheses of Empirical Work}

Several authors have discussed the role of road infrastructure expenditures in the performance of economies. The empirical review that we present includes the different works done outside Africa, in Sub-Saharan Africa and those made in Burkina Faso.

\subsubsection{Analyzes Performed Outside Africa}

Several authors have discussed the role of road infrastructure spending in the competitiveness of economies. Most of these studies show a positive correlation between the two variables.

Aschauer shows that investments in public infrastructure (including roads) induce increasing returns to scale in the production function of private agents [2-3]. These increasing returns lead in the medium and long term to a gain in economic productivity and thus to an improvement in longterm competitiveness. After estimating a factor productivity function, the author obtains elasticities in the order of 0.34 and 0.39 for the United States. Like this author, Barro and Barro and Sala-I-Martin have shown that spending on public infrastructure plays a leading role in improving the marginal productivity of private factors which, in short, enhance the overall productivity of the economy $[4,12]$.

Other analyzes have focused more on the contribution of basic infrastructure spending (such as the road) to improving the overall productivity of the economy. For example, Ford and Poret showed that the decline in public investment during the 1970s and into the mid-1980s in Organisation for Economic Co-operation and Development (OECD) countries was one of the causes of the observed slowdown in European productivity [15]. On the same analysis trajectory, Carlino and Voith show that the productivity of the American states is all the higher as the road network is dense [16].

Similarly, Kopp has concluded that investment in road infrastructure may have positive effects on the macroeconomic productivity of nations [5]. The author's analysis focused on thirteen (13) countries in Western Europe. The fixed effects estimate of the contribution of national road networks gives a significant coefficient of 0.71 . He explains that the countries in which companies are major users of road transport services, derive more the effects of investment in road infrastructure than countries where they consume relatively less.

Lafay studied the competitiveness of the European economy and explained how high raw material costs led to the decline of European competitiveness [17]. For him, it is not the implementation of the single market that has most affected European competitiveness in recent decades, but rather the high cost of raw materials which is closely linked to the cost of transport dominated by road transport. The author informs us that the high cost of road transport, which is closely linked to the state of the road infrastructure, considerably affects the cost of production of companies, which in turn negatively affects competitiveness.

In the same year, Mody and Reinfeld were more specific when they analyzed the factors determining the competitiveness of the Hong Kong, Singapore and Taiwan economies using a set of factors cost indicators and environmental quality [18]. With the main objective of analyzing the contribution of infrastructure to the economy competitiveness of these areas, the authors came to the conclusion that an improvement in transport infrastructure investments in general produces a reduction in supply costs, lower delivery times, speeds up production cycles and increases competitiveness. Thus, the authors place infrastructure (including road infrastructure) at the center of achieving and maintaining competitiveness.

Regarding the non-linearity of the relationship, several empirical studies have reported on the positive consequences of investments in public infrastructure in general and road infrastructure in particular on the competitiveness of the economy. Many of these analyzes indicate that the relationship is non-linear due to the existence of a threshold effect in externalities $[19,20])$.

Hulten, in his study on transport infrastructure, productivity and externality, pointed out that there is a strong positive non-linearity between investment in transport infrastructure in general and road investment, particularly in economic performance [14]. After studying the role of transport infrastructure investments in the performance of United States economies, Spain and India, the author shows that the impact of infrastructure investments, including road infrastructure, varies according to the level of development and extension of pre-existing infrastructure networks. For him, the more the road network is developed, the less the contribution of new investments to the gain of structural competitiveness of the economy.

\subsubsection{Analyzes Conducted in Sub-saharan Africa (SSA)}

In SSA, the economic literature on the contribution of road infrastructure investments to competitiveness remains quite limited and most of the existing studies have been limited to the assessment of the effects of certain economic factors such as exchange rate and market fix F. CFA on the price competitiveness of nations [21, 22]. However, some studies exist and have focused on the specific effect of road infrastructure spending on the competitiveness of the economies of some African regions. In this section, we also develop the effects of road infrastructure on productivity because, according Krugman, economic productivity is a good indicator of economic competitiveness [23].

Indeed, Dumont and Mesplesomps have analyzed the 
extent to which an increase in public infrastructure including road infrastructure makes it possible to achieve better commercial performances of the Senegalese economy as well as its competitiveness [24]. In their conclusions, the authors have established that a policy of expansion of public infrastructure in general has direct effects on domestic prices and the wage rate and thus on the commercial performance of the country's economy. This conclusion shows how the poor quality of transport infrastructure in general affects production efficiency, domestic prices and wages in lowincome countries.

In another register, Djahini studied the determinants of the competitiveness of the economies of thirty-five (35) countries in SSA, focusing on the effects of road infrastructure and financial development on the competitiveness of these countries [25]. Using the generalized moments method (GMM), the author estimates a panel model and arrives at a double conclusion concerning the expenditure on road infrastructures. First, there is a minimal level of road network from which the beneficial effect of road infrastructure on international competitiveness will begin to be felt. SSA countries would likely be below this optimal threshold. Secondly, the spatial distribution of road infrastructure in SSA is not optimal and this could help to limit the positive effects of investments in road infrastructure. In this regard, the author goes on to say that, in general and in many cases, infrastructure in SSA seems to be concentrated in large cities and capitals, which does not always favor the opening up of rural areas where the greatest concentration is concentrated. Part of the raw materials and agricultural resources that should be used as inputs for industries located in urban areas.

Studies carried out in Burkina Faso

For the specific case of Burkina Faso, the literature on the specific role of investment in road infrastructure in the country's structural competitiveness remains rather limited. Most of the authors who have been interested in the question of road infrastructure have studied their influence on the transport chain [26, 27]. However, a few rare analyzes have focused on the question of the competitiveness of the Burkinabe economy.

The World Bank after working on the effect of transport costs on the competitiveness of enterprises, concluded that the high cost of road transport itself depends on the age and low quality of road infrastructure and is one of the main causes of the lack of competitiveness of companies in Burkina Faso [28].

In the same order of analysis, the study by Sirima and al. expressed optimism about the analysis of competitiveness and economic growth of the country taking into account all sectors [29]. In their document, it is established that the strengthening of the competitiveness of the country's economy requires in principle infrastructure in general and road infrastructure in particular, capable of offering road transport services in quantity and good quality. As a result, the authors recommended a reorganization of the road transport sub-sector by improving the linearity and quality of road infrastructure. These measures are a saving action for economic competitiveness. On the same analysis trajectory, Sirpe and Christel and al. have established that investment in transport infrastructure in general and road infrastructure in particular is a way to increase the competitiveness of the country's economy $[26,30]$. However, the finding shows that the allocation of expenses to roads is not optimal. This situation does not ensure the productivity of the road transport sub-sector and therefore inhibits the competitiveness gain of the country's economy.

\section{Brief Review of Nonlinear Modeling Approaches}

In this section, three main approaches to nonlinear modeling are developed: regime change models, the quadratic approach, and the spline approach.

\subsection{Plan Change Models}

Regime change models, originally developed by Hansen and later extended by Gonzalez and al., are a recent alternative for determining thresholds for non-linear models [31-32, [33] Two major types of modeling exist namely chilled on brutal mechanism or model PTR (Panel Threshold Regression) proposed by Hansen and the smooth transition model in panel or PSTR model (Panel Smooth Threshold Regression model) proposed by Gonzalez and al., [32, 33].

In this PTR modeling, nonlinearity assumes that the explained variable is guided by two distinct regimes. In this model, the passage from a regime to another will constitute a period by comparing the variable transition to a threshold. As a result, the PTR approach assumes that the transition between the two regimes is brutal. The approach proposed by Gonzalez and al. is an extension of the PTR model and makes it possible to model situations where the transition from one regime to another is done gradually [33]. Thus, the PSTR approach highlights the continued character of the relationship and can also be considered as a model in which there are two extreme regimes between which there would be a continium regime. This approach has been used recently by Omrane Belguith and al. when they were interested in the empirical evaluation of the non-linear effects of the public debt on the economic growth of four countries (Egypt, Morocco, Tunisia and Turkey) [34].

The PTR and PSTR approaches make it possible to highlight the dynamics of the economic series according to the regimes in which they evolve. However, these models are more used and more suitable in the context of cylindrical panels [32]. As a result, these approaches are not included in this article.

\subsection{Quadratic Approach}

This is an approach to nonlinear modeling that highlights two regimes of the relationship between these two series [35]. In this article, this approach is based on the assumption of a change in the relationship between the structural 
competitiveness of the economy and the investment in road infrastructure. According to Lind and Mehlum the specification of the quadratic function can take two forms [36]. A U-shape and an inverted U shape.

When it is U-shaped, the theoretical specification consists of introducing the square of the investment in road infrastructure into the group of explanatory variables and then deriving the optimal share of investment. The model takes the following form:

$$
y_{t}=\alpha_{t}+\beta X_{t}+\gamma_{1} \operatorname{Inv}_{t}+\gamma_{2} \operatorname{In} v_{t}^{2}+\varepsilon_{t}
$$

In the equation (1),$y_{t}$ indicates the level of competitiveness, $\operatorname{In} v_{t}$ investment in road infrastructure, $X_{t}$ the other explanatory variables and $\varepsilon_{t}$ the terms of errors. The derivation of $y_{t}$ compared to $I n v_{t}$ given:

$$
\frac{\partial y_{t}}{\partial \operatorname{In} v_{t}}=\gamma_{1}+2 \gamma_{2} \operatorname{In} v_{t}
$$

At the point of optimal structural competitiveness, $\frac{\partial y_{t}}{\partial \operatorname{Inv} v_{t}}=0$. This makes it possible to derive the optimal share of investment in road infrastructure:

$$
\frac{\partial y_{t}}{\partial \operatorname{In} v_{t}}=0 \Leftrightarrow \gamma_{1}+2 \gamma_{2} \operatorname{In} v_{t}=0 \Leftrightarrow \operatorname{In} v^{*}=-\frac{\gamma_{1}}{2 \gamma_{2}}
$$

Equation (3) indicates the condition for determining the optimal share of investment in road infrastructure.

When is the quadratic representation of the inverted Ushaped e, the theoretical representation is of the form?

$$
y_{t}=\alpha_{t}+\beta X_{t}+\gamma_{1} \operatorname{Inv}_{t}+\gamma_{2} \operatorname{Inv}_{t}^{-1}+\varepsilon_{t}
$$

Applying the principle of derivation of equation (1) to (4), the optimal share of investment is given by $\operatorname{In} v^{*}=$ $\left(\frac{\gamma_{2}}{\gamma_{1}}\right)^{1 / 2}$.

\subsection{Spline Modeling}

This method is often used to estimate proportional differences before and after an optimal threshold [37]. According to the author, this approach can detect a gradual change in the evolution of an economic variable when the regression function is smooth at any finite number of points. The basic idea is to use several intervals for estimation involving the ordinary least squares method. Drawing from the author, the narrow approach is used in this article to determine the optimal investment interval for road infrastructure and to estimate the contribution of road infrastructure expenditures to the structural competitiveness of the economy before and after the optimum bound of the interval. In this case, this terminal is the optimal part of the investment in road infrastructure sought.

Therefore, the approach spline to verify the effectiveness of the optimal share of road infrastructure investments obtained in quadratic approach. The aim of the estimate is to find an unvaried variable relationship between structural competitiveness and investment in road infrastructure. For this, the model specification is as follows:

$$
y_{t}=\alpha_{t}+\beta X_{t}+\gamma_{1} \operatorname{Inv}_{t}+\gamma_{2}\left(\operatorname{Inv}_{t}-\operatorname{Inv}^{*}\right) Z+\varepsilon_{t}
$$

In the equation (5), in addition to the variables defined previously, the variable $Z$ is a dummy variable such as:

$$
Z=\left\{\begin{array}{l}
1 \text { si Inv } t \geq I n v^{*} \\
0 \text { otherwise }
\end{array}\right.
$$

In agreement with De Boor the principle of the full model is to estimate the parameters of the model until the effect of the investment on co- productivity changes direction [37]. For this, it is necessary to consider several bounds of intervals, one of which corresponds to the optimal part of the investment in road infrastructures noted $I n v *$ and to choose the terminal of interval which gives the highest coefficient of determination. These bounds represent the nodes in the author's analysis. This estimate is complex and difficult to apply because it requires several estimates before reaching the optimal threshold for investment.

For this, the proponents of the multivariate regression spline that are Friedman and Silverman propose to define, through a single equation, the set of intervals representing the different levels of investment in road infrastructure [38, 39]. Thus, the Spline regression takes the following form:

$$
y_{t}=\alpha_{t}+\beta X_{t}+\gamma_{1} \operatorname{Inv}_{t} \times d u m_{<T_{1}}+\gamma_{2} \operatorname{Inv}_{t} \times d u m_{T_{2}-T_{1}}+\gamma_{3} \operatorname{Inv}_{t} \times d u m_{\geq T_{2}}+\varepsilon_{t}
$$

The principle of estimation is to determine the proportion of the contribution of investment in road infrastructure to the competitiveness of the economy when it is below $T_{1}$, enter $T_{1}$ and $T_{2}$ and when the investment is above $T_{2}$. When the proportion decreases when moving from one interval to another, this implies a dynamic impact of investment in road infrastructure on the competitiveness of the economy. The condition of non-linearity and proportional change is given by:

$$
\left\{\begin{array}{l}
T_{1} \text { if } \gamma_{1}>0 ; \gamma_{2}<0 \text { and } \gamma_{3}<0 \\
T_{2} \text { if } \gamma_{1}>0 ; \gamma_{2}>0 \text { and } \gamma_{3}<0
\end{array}\right.
$$

These two conditions of the equation (8) allow both to determine the optimal part and to specify the different proportions before and after this part. It must be remembered, however, that in the estimation (8), only the significance of the parameters $\gamma_{1}, \gamma_{2}$ and $\gamma_{3}$ of instrumental variables is analyzed.

\section{Data Source}

The data used in this article are essentially secondary and cover the period from 1980 to 2015 , which is thirty-six years (36) years and come from two databases. Data on the share of investment in road infrastructure in the total investment budget were collected from Burkina Faso Infrastructure Minstry. The relative income gap, the export rate and the 
foreign penetration rate come from the West African States Central Bank (WASCB) database.

\section{Econometric Estimation Methods}

Two models are used for the estimation. This is the quadratic and spline approach. The non-inclusion of the change-over models is explained by the reasons given above. The idea of combining the two methods (quadratic and spline) aims to take into account the gradual evolution of the relationship between structural competitiveness and investment in road infrastructure. This is because the first approach avoids abrupt changes in slope and therefore provides a smoother regression curve and estimates the optimal share of road investment in the total investment budget. The second method makes it possible to detect a nonlinear impact of significant proportion beyond the optimal investment threshold without having a significant growth rate than that obtained below this threshold [40].

\subsection{Quadratic Model}

Starting from the situation of competitiveness by investment interval in road infrastructures presented above, we opt for the general form of the quadratic approach:

$$
\begin{aligned}
E R R_{t}= & \beta_{0}+\beta_{1} T e_{t}+\beta_{2} \text { Tpe }_{t}+\gamma_{1} \operatorname{Inv}_{t}+\gamma_{2} \operatorname{Inv}_{t}^{2}+\varepsilon_{t} \\
& E R R_{t}=\beta_{0}+\beta_{1} T e_{t}+\beta_{2} T p e_{t}+\gamma_{1} \operatorname{Inv}_{t} \times d u m_{<5 \%}+\gamma_{2} \operatorname{Inv}_{t} \times d u m_{15 \%-5 \%}+\gamma_{3} \operatorname{Inv}_{t} \times d u m_{\geq 15 \%}+\varepsilon_{t}
\end{aligned}
$$

In the equation (11), the dum represents the instrumental variables. The first takes the value 1 if the share of investment in road infrastructure in the total investment is less than $5 \%$ and 0 otherwise. The second variable takes the value 1 when the share of investment in road infrastructure in
After estimating the equation (9), a nonlinearity test confirms the presumption of the relation retained. This test starts from the following general quadratic form:

$$
E R R_{t}=\beta_{0}+\beta_{1} T e_{t}+\beta_{2} T p e_{t}+\gamma_{1} \operatorname{Inv} v_{t}+\gamma_{2} f\left(\operatorname{Inv} v_{i}\right)+\varepsilon_{t}
$$

In the equation $(10), f\left(I n v_{t}\right)$ is a continuous function representing the shape of the curve and $\operatorname{In} v_{i}$ is contained in an interval $\left[\operatorname{In} v_{l} ; \operatorname{In} v_{h}\right]$. Indeed, according to Lind and Mehlum, the nonlinear relation is in $\mathrm{U}$ when $\operatorname{In} v_{t}+\gamma_{2} f^{\prime}\left(\operatorname{In} v_{l}\right)<0<$ $I n v_{t}+\gamma_{2} f^{\prime}\left(I n v_{h}\right)$ [36]. Otherwise, the slope of the curve is negative at the beginning and positive after. If these conditions are violated, then the shape of the curve is U- inverted.

\subsection{Spline Model}

In accordance with the principles of spline estimation, it is necessary to specify the bounds $T_{1}$ and $T_{2}$ of the interval. As already pointed out by Mandri, the choice of this interval is not standardized [41]. It is done according to the type of data available and according to the country. In Burkina Faso, the average share of investment in road infrastructure in the total investment budget is $8.16 \%$ over the period $1980-2016$. So, the interval $[5 \% ; 15 \%]$ is retained given the finding made in the previous sections and the average share of investment in road infrastructure. The spline model is given as follows: investment tot al is between $5 \%$ and $15 \%$ and 0 otherwise. The third instrumental variable takes the value 1 if the share of investment in road infrastructure in the total investment is greater than $15 \%$ and 0 otherwise.

The variables of the model (11) are presented in Table 1.

Table 1. Variables retained.

\begin{tabular}{ll}
\hline Variables & Description \\
\hline & This is the variable explained. It represents the structural competitiveness indicator. The ERR is obtained from the following equation: \\
$E R R$ & $E R R=\frac{P I B_{b f}-P I B_{p c}}{P I B_{p c}}$ \\
& With $P I B_{b f}$ Burkina Faso's constant price real GDP and $P I B_{p c}$ the average real GDP at constant prices of Burkina Faso's competitors in \\
& WAEMU. \\
Inv & This is the total expenditure incurred for the construction and maintenance of roads. This is the variable of interest. \\
$T e$ & The export rate is obtained by relating real exports to real GDP. This variable captures the share of GDP devoted to meeting foreign \\
$T p e$ & demand. This is a control variable.
\end{tabular}

Source: author's construction.

In this table, the latter is obtained by performing a weighted average of the real GDP of the competing countries of Burkina Faso in WAEMU. The main purpose of weighting is to take into account the weight of each economy in the Union. The foreign penetration rate, $t x_{p e}=\frac{\text { import }}{C+I+G}$ with $C$ household consumption, $I$ business investment and $G$ public expenditure.

\section{Hypotheses Tests}

When working on time series, several preliminary tests are needed. This is mainly the normality of the errors and the stationarity of the series.

\subsection{Normality Test}

Given the dynamics of investments in road infrastructure and that of the competitiveness of the economy, it is necessary to verify the normality of the errors in order to have reliable statistics to perform Student's tests on the parameters of the model. The Jarque and Bera test, based on asymmetry and flattening, makes it possible to verify the normality of the errors. Based on the assumption of normality of errors against 
the alternative hypothesis of their non-normality, the result of the test gave a probability of 0.47 . [42]. This probability is greater than 0.05 , the null hypothesis of normality of residues is not rejected. Thus, this empirical evidence makes it possible to conclude that the errors are normal and this allows the continuation of the tests on the time series.

\subsection{Stationarity Study}

In order to appreciate the stationarity of the studied series, we apply the ADF test of Dickey and Fuller and that PP of Philips and Perron [43, 44]. The ADF test makes it possible to take into account the correlation between the different series and the PP improves the ADF test by providing a correction to nonparametric test, correlation and heteroscedasticity problems. The combination of these two tests makes it possible to have more appropriate results since when a variable is stationary in level for the ADF test and as a first difference for the PP test, it is the PP test which is retained. The hypothesis that is tested is the presence of a unitary root against the alternative hypothesis of the stationarity of series. The results of these two tests indicate that the relative income gap is stationary in second difference. Regarding the investment in road infrastructure, the export rate and foreign penetration, they are stationary in first differences.

\section{Results and Discussions}

\subsection{Results of Estimations and Interpretations}

The estimates of quadratic and spline gave the results shown in Table 2.

Table 2. Result of quadratic and Spline estimations.

\begin{tabular}{lll}
\hline Variables & Quadratic & Spline \\
\hline diff_Texp & $0.0741942 * *(2.30)$ & $0.0754279^{* *}(2.46)$ \\
diff_Tpe & $-0.0147381(-0.37)$ & $-0.0248578(-0.56)$ \\
diff_Inves_IR & $0.0110637 * * *(7.02)$ & - \\
inve_2 & $-0.0157841^{* * *}(-5.28)$ & - \\
& - & $0.0066965 * * *(3.18)$ \\
& - & $0.0178998^{* * *}(2.43)$ \\
adjusted & - & $-0.0129855^{* *}(-2.40)$ \\
\hline
\end{tabular}

Source: author estimation.

The results in Table 2 shows that the quadratic and spline estimates are adequate since the coefficients of determinations obtained are respectively 0.8452 and 0.8332 . These coefficients show that $84.52 \%$ and $83.32 \%$ of the variations in structural competitiveness are explained by the variables selected.

The results of the estimations show that the investment in road infrastructures admits a significant impact on the structural competitiveness of the economy of Burkina Faso for the two selected approaches. In addition, both estimates show that the export rate is a significant determinant of the structural competitiveness of the economy.

The quadratic estimate shows that investment in road infrastructure has a double impact on the structural competitiveness of the country's economy. In a first regime, investment in road infrastructure promotes the structural competitiveness of Burkina Faso's economy. Thus, in this phase, an increase of the first factor of $1 \%$ leads to a second improvement of $0.011 \%$, all other things being equal. In a second regime, however, the increase in road infrastructure expenditure hampers the structural competitiveness of the country's economy when its share of the total investment budget reaches a certain threshold. In this case, an improvement of the investment in road infrastructure of $1 \%$ leads to a decrease of the structural competitiveness of $0.016 \%$ all things being equal. Thus, these results of the quadratic approach make it possible to translate an inverted U-shaped relationship between investment in road infrastructure and the structural competitiveness of Burkina Faso's economy. The confirmation of this relation is given by the nonlinearity test of Lind and Mehlum [36].

\subsection{Validation and Determination of the Optimal Threshold}

Based on the null hypothesis of U-shaped nonlinearity against the alternative hypothesis of inverted U-shaped nonlinearity, this test avoids misinterpretation of the relationship between the two factors. By maximizing the quadratic equation, it makes it possible to determine the optimal threshold for the share of investment in road infrastructure in the total investment budget. The nonlinearity test provided a significant statistic of Lind and Mehlum [36] because its $\mathrm{P}$-value is zero. This empirical evidence makes it possible to reject the null hypothesis and to conclude that there is an inverted U-shaped nonlinearity. From there, the maximization of the quadratic model gives an optimal threshold of the share of investment in road infrastructure of $10.11 \%$.

With regard to spline estimation, it also highlighted the non-linearity between investment in road infrastructure and the structural competitiveness of Burkina Faso's economy. This estimate made it possible to identify, on the one hand, the differences in the impact of investment in road infrastructure on the structural competitiveness of the economy, and on the other hand, to confirm the optimal threshold obtained and to identify the interval between belonging to this threshold. The results of the estimate show that the coefficients of the first two instrumental variables are positive and significant and the third is negative and significant. With reference to the decision criteria set out above, it can be concluded that the optimal range that produces optimal structural competitiveness is [5\%, 15\%]. Thus, in this interval, any $1 \%$ increase in investment in road infrastructure contributes to improving the structural competitiveness of the economy by $0.018 \%$. However, when the share of investment in road infrastructure increased by $1 \%$ after $15 \%$, its contribution in the structural competitiveness declining and lies - 0,013\%. But when the share of investment in road infrastructure in the total investment budget is less than $5 \%$, an increase in expenditure on road infrastructure increases the structural 
competitiveness of the economy by $0.007 \%$. These results permit to conclude that beyond $15 \%$, an additional investment admits negatively affect the structural competitiveness of the economy.

In addition to investment in road infrastructure, the two estimates have established that the export rate is a significant determinant of the structural competitiveness of the economy. Indeed, the elasticities obtained are 0.074 for the quadratic estimate and 0.075 for the spline estimate. This result is in line with economic theory which establishes a positive relationship between a country's export rate and its external performance.

To fully understand this established link, it is necessary to break down Burkina Faso's export performance in WAEMU according to two types of factors. Indeed, two main groups of factors define the export rate. On the one hand, there are the demand factors that specify the conditions of market accessibility and, on the other hand, the factors relating to the productive capacity of the economy. In terms of demand factors, improved market access is driving increased export profitability through higher value-added net exports of road transport costs. This has already been mentioned by Sirpe [26]. Increasing the profitability of exports in turn contributes to the improvement of Burkina Faso's market share in the Union. Factors relating to productive capacity include the reduction in the cost of production resulting from the improvement of the productivity of the road transport sector. For this purpose, the impact of investments in road infrastructure can go even beyond the impact of capital expenditure.

\subsection{Discussion of Results}

The results of the quadratic and spline estimates enabled us to determine the non-linear effects of the investment in road infrastructures on the structural competitiveness of Burkina Faso's economy. The quadratic estimate to identify an optimal threshold of $10.11 \%$ and the spline estimate allowed to confirm this threshold since the optimal interval $5 \%$ at $15 \%$ obtained contains the optimal threshold.

For the explanation, we assume that with a total variable investment budget, Burkina Faso must devote $10.11 \%$ of its budget to invest in road infrastructure. In general, the state finances its expenditure on road infrastructure by debt, which is equivalent to a drain on the future income of the population. In agreement with Barro, the repayment of the loan is done by a tax on the income of the populations [10]. As a result, an improvement in road infrastructure investment is automatically followed by an increase in public investment in road infrastructure, which counteracts the decline in the marginal productivity of private capital (road infrastructure produces external savings). But when the share of investment in road infrastructure exceeds $10.11 \%$ of the total investment budget, the puncture observed on the income of the populations increases, which decreases at the same time the profitability of the private sector since it discourages the private investment. This situation leads to a sub-optimal gain in competitiveness, due to the crowding out of road infrastructure spending on private sector investment.

In addition, it is clear that the contribution of road infrastructure investment to the structural competitiveness of the economy varies according to whether it is lower or higher than the optimal share of investment. This is not surprising because according to Hulten, there is a strong non-linearity between transport infrastructure investments and economic growth [14]. Greater investment in underdeveloped or congested road networks generates more competitiveness gains. This result is shared by the OECD for whom these effects, which reflect the influence of infrastructure in general on the overall efficiency of the economy, seem stronger when the initial level of infrastructure provision is low [11]. In this case, the decline in the contribution could be explained either by a decrease in the efficiency of the roads due to a bad distribution, or by a decrease of the productivity of the private sector due to the crowding out of the public expenditure on the expenses private, either by both elements at a time.

In short, road infrastructures have a long life, the quality of which declines over time if they are not maintained. Thus, when the expenses are not made regularly and optimally, the quality of the service rendered decreases. Anything that proves that extra costs are imposed on companies in their production processes, which reduces the productivity of the private sector and hence the overall productivity. New road investments thus help maintain the existing road infrastructure network and develop new capacity in strategic areas of the country and strengthen the structural competitiveness of the economy.

Regarding the debate on the optimal share of investment, authors like Djahini and Keho had already wording its existence respectively for the Cote d'Ivoire and for the countries of South Sahara Africa without determining it [25, 45]. Unlike these authors, estimates were used to determine optimal investment gap in road infrastructure that ensures optimal structural competitiveness with regard to Burkina Faso. From that moment, it seems reasonable to say that the question of the existence of an optimal share of investment in road infrastructure had the merit of being asked.

\section{Conclusion}

This article aimed at estimating the non-linear effects of road infrastructure investment on the structural competitiveness of Burkina Faso's economy. To this end, we adopted a progressive methodological approach from the presentation of theoretical and empirical foundations of the relationship between economic competitiveness and investment in road infrastructure in the review of approaches to nonlinear modeling. Thus, two models have been estimated to test the hypothesis that an optimal share of investment in road infrastructure is needed to ensure optimal structural competitiveness. They are namely the quadratic estimate and the Spline approach. The quadratic estimation has determined an optimal percentage of road infrastructure investment from which there is a gradual change in the 
relationship between the structural competitiveness of the economy and investment in road infrastructure. The spline estimate confirmed this optimal share and was used to determine the optimal investment interval for road infrastructure.

The quadratic estimation revealed an inverted U-shaped non-linearity between investment in road infrastructure and the structural competitiveness of Burkina Faso's economy. Thus, an optimal threshold of $10.11 \%$ allowed to highlight two distinct regimes. When the share of investment in road infrastructure is less than or equal to this threshold, investment in road infrastructure is favorable to structural competitiveness. On the other hand, for a share higher than the threshold, the investment in road infrastructures compresses the structural competitiveness of the economy. Regarding spline estimation, it also highlighted the non-linearity between investment in road infrastructure and the structural competitiveness of Burkina Faso's economy. The optimal interval obtained is [5\%, $15 \%$ ]. This interval contains the optimal threshold obtained through the quadratic approach and thus makes it possible to confirm it. In this interval, an increase in investment in road infrastructure of $1 \%$ improves structural competitiveness by $0.018 \%$. But above $15 \%$, an increase in investment in road infrastructure of $1 \%$ leads to a decrease in structural competitiveness of $0.013 \%$.

These results make it possible to qualify the question of the contribution of road infrastructure spending to economic performance. Thus, in the light of these results, the implication of economic policy that emerges is that an increase of investments in road infrastructures constitutes a policy of gaining optimal structural competitiveness of the country's economy. In this purpose, the share of the investment in road infrastructure within the total investment budget must be between $5 \%$ and $15 \%$.

\section{References}

[1] Smith, A. (1776). An Inquiry into the Nature and Cause of the Wealth of Nations. Oxford University Press.

[2] Aschauer, DA (1989a). Is public expenditure productive? Journal of monetary Economics, 23, pp 177-200.

[3] Aschauer, DA (1989b). Public Investment and Productivity Growth in the Group of Seven. Economic Perspectives, pp 17-25.

[4] Barro, RJ (1990). Gouvernment spending in a simple model of endogenous growth. Journal of Political Economy, pp 125130.

[5] Kopp, A. (2007). Incidence des investissements routiers sur la productivité macroéconomique-réevaluation du cas de l'Europe Occidentale. OCDE/CEMT de recherche sur les transports, pp 79-102.

[6] Banque mondiale. (2017). Evaluation des politiques et des institutions en Afrique. Banque mondiale.

[7] MI. (2016). Programme d'investissement public. Ougadougou: Ministère des infrastructures.
[8] BCEAO. (2016, 07 18). Base de données. Récupéré sur Banque Centrale des Etats de l'Afrique de l'Ouest www.bceao.int: http://www.bceao.int

[9] Roy, W. (2004). L'investissement public dans les infrastructures de transport est (il source de croissance endogène? Lyon 2: Laboratoire d'économie des transports.

[10] Barro, RJ (1997). Determinants of Economics Growth: A Cross-Country Empirical Study. MIT Press.

[11] OCDE. (2009). L'investissement en infrastructures: liens avec la croissance et rôle des politiques publiques. Réformes économiques.

[12] Barro, RJ, et Sala-I-Martin, X. (1996). La croissance économique. Collection sciences économiques, MCGRAWHILL/EDISCIENCE.

[13] Bamba, NL (2005). L'économie monetaire de la Cote d'Ivoire: une économie d'endettement ou une économie de marché financier? CAPEC.

[14] Hulten, CR (2007). Infrastructures de transport, productivité et externalité. OCDE.

[15] Ford, R., and Poret, P. (1991). Infrastructure and Private Sector Productivity. OECD, 1-28.

[16] Carlino, G., and Voith, R. (1992). Accounting for Differences in Aggregate State Productivity. Regional Science and Urban Economics, 597-617.

[17] Lafay, G. (1995). La compétitivité européenne face au durcissement de la concurrence internation. Révue économoique, 679-689.

[18] Mody, A., and Reinfeld, W. (1995). Advanced Infrastructure for Time Management: The Competitiveness Edge in East Asian. The Wold Bank, Washington.

[19] Fernald, JG (1999). Roads to Prosperity? Assessing the Link between Public Capital and Productivity. American Economic Review.

[20] Sutherla nd, D., Araujo, S., Egert, B., and Kozluk, T. (2009). Infrastructure Investment: Links to Growth and the Role of Public Policies. OECD.

[21] Bogetic, Z., Espina, C., and Noer, J. (2007). Cote d'Ivoire: Competitiveness, Cocoa and the Real Exchange Rate. The World Bank.

[22] Lessoua, A., et Sokic, A. (2012). Union monétaire et compétitivité comparée: les cas de la zone euro et de la zone CFA. Bureau d'économie théorique et appliquée (BETA), 19-25.

[23] Krugman, P. (1994). Competitiveness: A Dangerous Obsession. Foreign Affairs.

[24] Dumont, JC, et Mesple-Somps, S. (2000). L'impact des infrastructures publiques sur la compétitivité et la croissance: Une analyse en EGC appliquée au Sénégal. Développement Insertion Internationale (DIAL).

[25] Djahini, E. (2015). The Main Determinants of International Competitiveness in Sub-Saharan Africa. Munich Personal RePEC Archive, 1-27.

[26] Sirpe, G. (1994). Le transport routier de marchandises au Burkina Faso: un essai d'analyse économique. Ouagadugou: CEDRES ETUDES. 
[27] Sirpe, G. (2003). Transport routier et ecoulement des produits agricoles: une analyse économique de l'influence des transports routiers sur les mouvements interrégionaux de céréales au Burkina Faso. Ouagadougou: Press Universitaires de Ouagadougou.

[28] Banque Mondiale, (2009). Rapport sur le développement dans le monde. Banque mondiale.

[29] Sirima, B., Monga, C., Bambara, D., Pare, N., Savadogo, K., N'Cho-Oguie, C., \& Charleir, F. (2001). Competitiveness and Economic Growth: policies, strategies and actions. Ouagadougou: Ministry of Economy and Finance of Burkina Faso.

[30] Christel, A., et AFUA, E. (2010). Coûts du transport et de la logistique sur le corridor Tema-Ouagadougou. Agence Américaine pour le De veloppment International.

[31] Hansen, BE (1996). Inference when a Nuisance Parameter is not Identified Under the Null Hypothesis. Econometrica, 413430.

[32] Hansen, BE (1999). Threshold Effects in Non-dynamic Panels: Estimation, Testing and Inference. Journal of Econometrics, 345-368.

[33] Gonzalez, A., Teräsvirta, T., and Dijk, VD (2005). Panel Smooth Transition Regression Models. Stockholm School of Economics.

[34] Omrane Belguith, S., Chakrou n, M., et Badr Gabsi, F. (2017). Effets non linéaires de la dette publique sur la croissance économique des pays MENA: évaluation empirique à l'aide d'un modèle PSTR. Revue Economique et Monétaire (REM) (21), 1-24.

[35] Cai, TT, and Low, MG (2005). Nonquadratic estimators of quadratic. The Annals of Statistics, 33 (6), 2930-2956.
[36] Lind, J., and Mehlum, H. (2007). With or Without? The appropriate test for a U-shaped relationship. Munich Personal RePEc Archive (MPRA), 1-13.

[37] De Boor, C. (1978). A Pratical Guide to Spline. SpringerVerlag.

[38] Friedman, JH (1984b). Classification and Multiple Response Regression Through Projection Pursuit, Dept of Statistic, Stanford University.

[39] Silverman, BW (1985). Some Aspects of Spline Smoothing Approach to Non-Parametric Regression Curve Fitting. Journal of the Roy Stat Soc, 1-52.

[40] Partillo, CH, Poirson, H., and Ricci, L. (2011). External Debt and Growth. Revue of Economics and Institutions.

[41] Mandri, B. (2015). Effets seuils de la dette publique sur la croissance économique. Rabat - Agdal: Laboratoire d'Economie Appliquée, Université Mohammed V.

[42] Jarque, CM, and Bera, AK (1984). Testing the Normality Assumption in Limited Dependant Variable Models. International Economic Review.

[43] Dickey, D., and Fuller, W. (1981). Likelihood ratio statistics for autoregressive time series with unit root. Econometrica, 49 (4).

[44] Philips, P., and Perron, P. (1988). Testing for Unit root in Time Series Regression. Biometrika.

[45] Keho, Y. (2004). Impact de l'investissement public sur la croissance en Côte d'Ivoire. Politique Economique et Développement (PED). 